\section{CONCLUSIONS}

Linking a telephonic counseling program to rural primary care practices to assist patients in behavior change was well accepted and welcomed by clinicians. Once enrolled, patients seemed to value the program, but additional strategies beyond a 1 -time physician referral are needed to increase patient participation.

To read or post commentaries in response to this article, see it online at http://www.annfammed.org/cgi/content/full/3/Suppl_2/S43.

Key words: Sedentary lifestyle; smoking; telephone counseling; community/public health; health promotion/disease prevention; behavior change; rural health services

Submitted December 21, 2004; submitted, revised, February 21, 2005; accepted March 16, 2005.

Funding support: This project was supported by Prescription for Health, a national program of The Robert Wood Johnson Foundation with support from the Agency for Healthcare Research and Quality.

Acknowledgments: We extend special thanks to the practices in the Kentucky Ambulatory Network that hosted this project: Pennington Family Medicine, Richmond, Ky; Dartt and Hurt, PSC, Danville, Ky; Inez Medical
Clinic, Inez, Ky; Knox Family Medicine, Barbourville, Ky; Primary Care Associates, Glasgow, Ky; Carter County Clinic, Olive Hill, Ky; Dix River Family Medicine, Stanford, Ky; North Gerrard Family Medicine, Lancaster, Ky; Richard Miles, MD, Russell Springs, Ky; James Ferrell, MD, Paris, Ky; Kent Davis, MD, Paris, Ky; William Pratt, MD, London, Ky; Tammy Brown, MD, Albany, Ky; and James Roach, MD, Midway, Ky.

\section{References}

1. Rabius V, McAlister AL, Geiger A, Huang P, Todd R. Telephone counseling increases cessation rates among young adult smokers. Health Psychol. 2004;23:539-541.

2. Pinto BM, Friedman R, Marcus BH, Kelley H, Tennstedt S, Gillman MW. Effects of a computer-based, telephone-counseling system on physical activity. Am J Prev Med. 2002;23:113-120.

3. Ramsbottom-Lucier M, Emmett K, Rich EC, Wilson JF. Hills, ridges, mountains, and roads: geographical factors and access to care in rural Kentucky. J Rural Health. 1996;12:386-394.

4. Zhu SH, Stretch V, Balabanis M, Rosbrook B, Sadler G, Pierce JP. Telephone counseling for smoking cessation: effects of single-session and multiple-session interventions. J Consult Clin Psychol. 1996;64:202-211.

5. Smith PM, Cameron R, McDonald PW, Kawash B, Madill C, Brown KS. Telephone counseling for population-based smoking cessation. Am J Health Behav. 2004;28:231-241.

\title{
Establishing a Family-Based Intervention for Overweight Children in Pediatric Practice
}

Ellen R. Wald, $M D_{i}{ }^{1}$ Linda Ewing, $P b D, R N_{i}{ }^{2}$ Patricia Cluss, $P b D_{i}{ }^{2}$ Sheri Goldstrobm, $P b D_{i}{ }^{2}$ Lynne Cipriani, $R N_{i}{ }^{1}$ Katbleen Colborn, $B S^{1}$

${ }^{1}$ Children's Hospital of Pittsburgh, University of Pittsburgh School of Medicine, Pittsburgh, Pa

${ }^{2}$ Western Psychiatric Institute and Clinic, University of Pittsburgh School of Medicine, Pittsburgh, Pa

Ann Fam Med 2005;3(Suppl 2):S45-S47. DOI: 10.1370/afm.366.

Conflicts of interest: none reported

CORRESPONDING AUTHOR

Ellen R. Wald, MD, University of Pittsburgh School of Medicine, Children's Hospital of Pittsburgh, 3705 Fifth Ave, Pittsburgh, PA 15232, ellen.wald@chp.edu

\section{PURPOSE}

W e performed a pilot study in 2 pediatric practices to (1) increase the identification of overweight children by the primary care clinician and encourage their referral to an "in-office" family-based intervention, and (2) test the feasibility of an intensive family-based intervention using behavior modification to alter nutrition and physical activity in children who are overweight.

\section{METHODS}

The intervention was conducted at 2 community pediatric practices in western Pennsylvania. One rural practice, approximately 40 miles from Pittsburgh, serves a predominantly white population with low to middle income. The second practice serves a racially and economically diverse urban population in the city of Pittsburgh. Each practice has 10 physicians and 1 nurse-practitioner.

During a 90-minute interactive session, physicians were trained in the use of brief motivational strategies to assist parents in taking steps toward healthier behavior relating to nutrition and physical activity. The identification of overweight children was facilitated by introduction of routine systematic measurement and recording of body mass index (BMI), which was plotted according to sex and age on a color-coded BMI chart, resulting in visual confirmation of the degree of overweight. Physi- 
cians used their new motivational interviewing skills to introduce and refer patients to the intervention. Children between 8 and 12 years of age identified by their primary care clinicians as being above the 85 th percentile for BMI and their families were eligible.

The intervention, consisting of separate group counseling for children and parents (approximate group size $=8$ ), was delivered over 6 months: 8 group sessions in the first 3 months and 3 individual follow-up sessions with the counselor in the next 3 months. Ten minutes of one-on-one counseling for each child-parent dyad was provided at 7 of the 8 group sessions. The intervention was delivered by behavioral psychologists, nurse-educator trainees, or both.

To learn about parents' perceptions of their child's weight and physical activity, and their concern about these issues (in preparation for the clinicians' motivational interview), we gave a 7 -item questionnaire to parents of all children between 3 and 12 years of age being seen for a health maintenance visit. The questionnaire, completed in the waiting room, asked parents to indicate whether their child was of normal weight or overweight.

We performed the following activities to determine outcomes: (1) assessment of documentation of the recording of BMI in the medical record, (2) exit interviews conducted with parents before and after the intervention was implemented to assess whether physicians discussed BMI as part of their routine feedback to parents, (3) assessment of physicians' self-reported confidence in the use of counseling skills related to overweight as determined by a questionnaire administered before and after the intervention, and (4) tracking of family attendance at group intervention sessions.

\section{LESSONS LEARNED}

The 2 practices that were sites for this pilot study were selected because of their size, patient composition, and general interest. Physicians and office staff were very interested in developing skills to help solve the problem of obesity in children. A questionnaire completed by 21 physicians before and 2 months after their skills session showed a notable increase in physician confidence with regard to counseling about nutrition and weight status. Informal discussions with physician participants indicated a desire for more "practice" sessions. Nurse-practitioners and staff members (nursing assistants) displayed their interest in the intervention program by volunteering to be trained to lead the parent and child group, respectively.

A chart audit conducted in both practices indicated that the introduction of systematic measurement and recording of BMI was easily accomplished. A colorcoded BMI chart used to illustrate the child's BMI was placed in the medical record, and a miniature copy was provided to the parent. Exit interviews with parents conducted before ( 24 interviews) and after ( 27 interviews) the training sessions for primary care clinicians and the introduction of the color-coded chart showed a substantial increase in the discussion of eating habits and physical activity.

Responses on the questionnaire indicated that parents of young children ( 3 to 5 years of age) who were overweight rarely recognized that their children were overweight (Table 1). Likewise, parents of children at risk for overweight ( $>85$ th but $<95$ th percentile) infrequently acknowledged that their children were above the usual standards for weight. Accurate parental perception of overweight in children was most often noted in older children ( 8 to 12 years of age), more often in girls than in boys, and more often in those with the highest BMI. Ninety-three children had a BMI between the 85 th and 94 th percentile and were classified as at risk for overweight. Only 7 (7.5\%) of 93 mothers identified their children as above normal weight, compared with $70(49.3 \%)$ of 142 mothers of children in the 95 th percentile or higher.

Use of office staff to lead a behavioral intervention requires further study. Identification and training of appropriate individuals are very time-consuming, and there is uncertainty regarding whether the "train the trainer" model will be sufficient to produce generally effective results. Practical issues emerge, such as the need to train additional individuals as backup for unexpected absences (eg, illness and moves).

Thirty-seven $(50.5 \%)$ of 73 families who began the intervention completed at least 6 of 8 group sessions and 1 of 3 follow-up sessions. This program required a large time commitment and a change of habits on the part of the parent to create a successful environment for the child. It also required that all caregivers in the child's home were congruent in their appreciation of the problem and committed to its solution. If any household member was not supportive, it was

\section{Table 1. Proportion of Parents of Overweight Children ( $\geq 95$ th Percentile for BMI) Who Perceive Their Children as Overweight}

\begin{tabular}{llll}
\hline $\begin{array}{l}\text { Child's } \\
\text { Age }\end{array}$ & $\begin{array}{c}\text { Boys } \\
\% \text { (No.) }\end{array}$ & $\begin{array}{c}\text { Girls } \\
\% \text { (No.) }\end{array}$ & $\begin{array}{c}\text { Total } \\
\% \text { (No.) }\end{array}$ \\
\hline $3-5$ y & $12.5(3 / 24)$ & $25(4 / 16)$ & $17(7 / 40)^{\dagger}$ \\
$6-8$ y & $32(6 / 19)$ & $60(15 / 25)$ & $48(21 / 44)$ \\
$9-12$ y & $35(18 / 51)$ & $89(24 / 27)$ & $72(42 / 58)$ \\
Total & $29(27 / 94)^{*}$ & $63(43 / 68)^{*}$ & $137(70 / 142)$ \\
\hline BMI = body mass index. & & \\
$* P<.001$ (boys vs girls). & & \\
$\dagger P<.001$ (younger children vs older children) $(7 / 40$ vs 63/102).
\end{tabular}


extremely difficult to create a successful environment. Families discontinued participation for a variety of reasons. If we can identify these reasons prospectively, we may be able to discourage some patients from beginning the intervention until potential barriers are resolved. It is desirable to delay participation of a family until there is a greater chance for success.

\section{CONCLUSIONS}

Pediatricians and their office staff were very interested in strategies to help identify and treat children who were overweight. Systematic identification of overweight children was easily introduced into the practice setting. Parents of young children ( 3 to 5 years old) who are overweight and of children at risk for over- weight infrequently recognize that their children are above the usual standards for weight. Accurate parental perception more often occurs in older children, in girls, and in children with the highest BMI. An in-office family-based intervention focused on behavior modification can be successful if barriers are identified and reduced.

To read or post commentaries in response to this article, see it online at http://www.annfammed.org/cgi/content/full/3/Suppl_2/S45.

Key words: Overweight; obesity; parents; child; pediatrics; primary care; nutrition; behavior modification; diet; physical activity

Submitted November 19, 2004; submitted, revised, February 9, 2005; accepted February 14, 2005.

Funding support: This project was supported by Prescription for Health, a national program of The Robert Wood Johnson Foundation with support from the Agency for Healthcare Research and Quality.

\title{
It Takes a Partnership: The Value of Collaboration in Developing and Promoting a Web Site for Primary Care Patients
}

\author{
Alex H. Krist, $M D_{i}{ }^{1,2}$ Steven H. Woolf, MD, MPH, ${ }_{i}{ }^{1,3}$ Stephen F. Rotbemich, MD, MS ${ }^{1}$ Robert E. Jobnson, PbD, ${ }^{1,4}$ \\ Diane B. Wilson, EdD, MS, RD \\ 'Department of Family Medicine, Virginia Commonwealth University, Fairfax, Va \\ ${ }^{2}$ Fairfax Family Practice Residency, Virginia Commonwealth University, Fairfax, Va \\ ${ }^{3}$ Department of Preventive Medicine and Community Health, Virginia Commonwealth University, Fairfax, Va \\ ${ }^{4}$ Department of Biostatistics, Virginia Commonwealth University, Fairfax, Va \\ ${ }^{5}$ Department of Medicine, Virginia Commonwealth University, Fairfax, Va \\ Ann Fam Med 2005;3(Suppl 2):S47-S49. DOI: 10.1370/afm.361.
}

Conflicts of interest: none reported

CORRESPONDING AUTHOR

Alex H. Krist, MD, 3825 Charles Stewart Dr, Fairfax, VA 22033, ahkrist@vcu.edu

\section{PURPOSE}

The purpose of our project was to develop a specialized Web site that helps patients pursue healthy eating, physical activity, smoking cessation, and moderation of alcohol consumption, and to integrate use of the Web site into primary care practice.

Encounters between patients and clinicians are a unique opportunity to promote healthy behaviors. Patients cite the advice of their physician as an important motivator for lifestyle change. ${ }^{1}$ Unfortunately, health care professionals are often ill-equipped to deliver the intensive counseling that is necessary to effect sustained behavior change. Among the various barriers-which include inadequate time, reimbursement, and counseling skills_-are the limitations most clinicians face in helping patients obtain the information they need for behavior change. ${ }^{2,3}$

To address these information needs, we worked with 6 primary care practices within the Virginia Ambulatory Care Outcomes Research Network (ACORN) to develop a Web site that patients could use at home to identify risky behaviors and enjoy convenient personal access to the best local and national resources on healthy behaviors. We aimed to both develop and evaluate the Web site within the 16-month grant period. The Web site's effectiveness was assessed with a pretest-posttest design, the results of which will 